\title{
A comunicação multimédia no neorritualismo das festas transe
}

Emília Simão ${ }^{1}$

Sérgio Tenreiro de Magalhães²

Resumo: O culto da música electrónica nos rituais pós-modernos não se resume à reverência de um estilo musical, mas representa um novo estado de coisas. Existe uma relação entre o xamã do passado e o xamã do presente, incorporado pela figura do $D J$. Ambos são o elemento-guia de um ritual, ao propiciarem viagens através de estados de consciência alternativos, exteriorizando o som, por um lado, de forma arcaica e, por outro, de forma tecnologicamente sofisticada.

Palavras-chave: comunicação, multimédia, neorritualismo, música electrónica, transe psicadélico.

Abstract: The cult of electronic music in post-modern rituals is not limited to a reverence of a musical style, but it represents a new state of things. There is a relationship between the shaman of the past and the shaman of the present, embodied by the figure of the DJ. Both are the guiding element of a ritual, while stimulating "trips" through alternative states of consciousness, externalizing the sound in two ways: an archaic form and in a technologically sophisticated form.

Keywords: communication, multimedia, neo-ritualism, electronic music, psytrance. 
Em finais do século XX, deu-se início a um raro intervalo da história, cuja característica é a transformação da nossa cultura material pelos mecanismos de um novo paradigma tecnológico (CASTELLS, p. 2000). Os modernos instrumentos electrónicos, incorporando na sua estrutura a combinação de sons essencialmente instrumentais, terão criado um novo poder de encantamento, sustentado pela música electrónica e pelas tecnologias multimédia, enquanto pilares de actuais manifestações neotribais?

Estará o homem pós-moderno a viver numa lógica de retroactividade, ao recriar o tribalismo na era tecnológica, através de celebrações em que se vive o culto da música electrónica, despertando uma nova relação entre o homem e máquina, a arte e as tecnologias e os xamãs do passado e os do presente? Poderá o DJ (disk jockey) comparar-se ao xamã, e terá a tecnologia uma faceta xamânica? A música electrónica é, na sua mais alta especificidade, o som de uma máquina manipulada pelo homem? A sincronia e a interactividade das tecnologias multimédia como extensões artificiais dos sentidos serão indispensáveis para a celebração dos rituais da tribo transe?

Na sociedade pós-moderna, existe uma necessidade de estar e de partilhar, e esta necessidade materializou-se através da formação de grupos, cujos membros partilham uma identidade simbólica, originando o neotribalismo (MAFFESOLI, 2000). Do contexto tribal sempre advieram cerimónias e rituais, praticados com o intuito de estabelecer vínculos sagrados com a natureza, os espíritos e os deuses; e, através de sonoridades repetitivas e outras evocações litúrgicas, foram-se criando elos de ligação ao transcendente. Já as sociedades primitivas mantinham rituais em que a dança e a projecção da luz (através do fogo) e a do som (através de instrumentos arcaicos de percussão) criavam ambientes propícios a determinadas formas alteradas de consciência. Essas culturas e práticas foram quase sucumbindo ao longo dos tempos, até que alguns milhares de indivíduos têm vindo a agruparse, essencialmente nas últimas duas décadas, em festas - como rituais de dança, união e ligação ao transcendente - , vivendo um tribalismo de raízes 
arcaicas, abençoado pelas maravilhas da sociedade tecnológica, em que a música electrónica assume o papel de maior relevo.

\section{Do ritual tribal à festa da tribo transe}

O culto da música electrónica nos rituais pós-modernos não se resume à reverência de um estilo musical, mas representa um novo estado de coisas. Em finais do séc. $X X$, nos anos 70, vivia-se em Goa, na Índia, uma intensa cultura psicadélica, celebrada em festas com cores exuberantes, traduzidas por manifestações artísticas e visionárias, inspiradas por experiências alucinogéneas. Essa nova cultura, essencialmente trazida por estrangeiros, era por muitos seguida como uma verdadeira filosofia existencial (LARKIN, 2003). A música electrónica vai-se inserindo nesses festejos, dos quais emergiram as primeiras manifestações do Goa transe e, em sequência, do transe psicadélico, estilos musicais que se mantiveram até hoje sempre em constante movimento e mutação, muito para além das fronteiras de Goa. As festas difundiram-se (e, em paralelo, os estilos de vida alternativos dos seus nativos), passando a ocorrer um pouco por toda a parte, assumindo-se como veículos para outras latitudes, espirituais e metafísicas, e de amplificação de consciência (CARVALHO, 2007).

As festas dividem-se usualmente em dois momentos-chave, a noite e o dia, tendo a primeira uma presença tecnológica muito mais forte, em que toda a componente multimédia está no seu auge. Metaforicamente falando, o dia é a celebração e a consolidação do ritual invocado durante a noite, forjado numa mescla de luar, sombras e tecnologias.

O alfabeto veio dar um estatuto especial à significação e desmistificou de certa forma a magia do mundo tribal (DAVIS, 2002). Poderá ser por esse motivo que esse estilo essencialmente musical e desprovido de letras tenha feito renascer o elo perdido com a magia daquele mundo tribal, com a natureza e com a essência espiritual do homem. A música e a dança, nas suas formas mais elementares, são, desde os primórdios, manifestamente associadas a rituais, 
como recursos para experiências místicas. Essa comunhão é reconstituída com o culto da música electrónica, em que as experiências individuais são incorporadas por um colectivo em perfeita sintonia, como acontece nas festas transe.

Segundo o guru da ritualização da música electrónica, o DJ Goa Gil, a dança é uma meditação activa, que celebra a comunhão com a natureza e o universo através da música transe, um processo que ele designa de "redefinição do antigo ritual tribal de dança para o século XXI" (MCATEER, 2002).

Portugal é um dos países em que as manifestações da cultura transe têm sido mais vigorantes, desde as festas, que vão acontecendo um pouco por todo o país, aos festivais, que reúnem milhares de pessoas. O Boom Festival, exemplo de um dos maiores festivais do género da panóplia internacional, é realizado em Portugal bienalmente, e contou em 2010 com a sua $8^{a}$ edição, reunindo milhares de pessoas de vários países. Trata-se de um dos pontos altos dos encontros neotribais da actualidade.

De todo esse encadeamento emergiram as três principais perguntas de investigação: O culto da música electrónica terá despertado uma nova relação entre homens e máquinas, arte e tecnologias, xamãs do passado e xamãs actuais? A tecnologia como veículo terá uma faceta xamânica, na medida em que permite a criação de mundos imaginários e estados de consciência alternativos? A tecnologia multimédia como extensão artificial do som, da luz e do próprio local será responsável para que o ritual aconteça?

\section{Metodologias de investigação}

Foi nas premissas da pesquisa qualitativa que esta investigação se sustentou, recorrendo-se a três métodos: revisão de literatura, entrevistas com peritos, e observação participante. A revisão de literatura forneceu dados teóricos, permitindo respostas e esclarecimentos a algumas questões. As entrevistas com peritos permitiram recolher contributos substanciais de Pedro Carvalho, produtor, encenador, artista plástico e cofundador do Boom Festival; 
do DJ Daniel Bernardo, de nome artístico Menog, compositor e empresário discográfico na área; do DJ Goa Gil, figura emblemática desse universo, um dos responsáveis pelas primeiras manifestações do transe como estilo musical de raízes electrónica; e ainda de Artur Mendes, um dos responsáveis pela actual produção do Boom Festival. Na observação participante, foram reunidas notas de campo com registos detalhados, e algumas reflexões em ambiente natural da festa.

\section{Da música electrónica ao transe psicadélico}

Nas décadas de 50 e 60, os compositores com recurso às tecnologias disponíveis em estúdio instituíram a designação de música electrónica para marcar o seu território, resultante basicamente da mistura e da reciclagem de amostras de sons previamente criados e gravados, aos quais se adicionavam fragmentos musicais de outros géneros. A composição da música electrónica tem assumido até hoje essa forma fractal, em que, a partir de objectos organizados e similares, se acrescentam detalhes sonoros que se desdobram infinitamente. Esta matéria-prima não se limita nem à sua composição inicial nem à final, passando a integrar uma gigantesca base de sons mutantes e em constante aperfeiçoamento, numa existência quase autossustentável.

No que diz respeito à música electrónica de dança, o house e o techno foram os principais grandes movimentos do séc. $X X$, tendo conduzido o panorama musical mundial a novos padrões e elevado a audibilidade para um outro status. Em parte na sequência do declínio das raves urbanas, emergiram as festas, proporcionando uma espécie de reconciliação das elites e dos freaks com a música electrónica. A arte ancestral e as novas tecnologias começaram aqui a assumir uma conexão, invadindo o campo uma da outra, e resultando numa nova relação entre ambas. 


\section{Novas relações entre homem, máquina, arte e tecnologia}

A relação de dependência tecnológica que o homem tem vivenciado levou a um afastamento relacional com a natureza tão desmedido que a regressão e a procura pelo elo perdido talvez fossem a única solução para reencontrar a sua identidade. O hedonismo e o êxtase vinculados às festas podem ser os novos catalisadores do renascer do sentimento de pertença e do espírito tribal, dentro do cenário pós-moderno, tecnológico e global em que vivemos.

Considerando o culto da música electrónica uma realidade dos tempos pós-modernos, é visível que ela despertou uma nova relação entre os homens e as máquinas, a arte e as tecnologias. As novas linguagens e as novas poéticas no contexto da música electrónica deram origem a novos cultos e a novas relações entre homem e máquina e entre objecto artístico e tecnologia. O compositor criou uma relação solitária com as suas ferramentas digitais, demonstrando uma relação entre o homem e a máquina que vai da axiomática relação física à relação afectiva, e na qual a música, como expressão artística e de um ideal estético, é criada, manipulada e veiculada pela máquina - que, por sua vez, é orientada pelo homem.

O transe, enquanto género musical de influências psicadélicas, é concebido para provocar sensações intensas e alterações da experiência consciente, em que é visível a interacção da ciência, da estética e da psique e em que a multimédia tem um papel de destaque. A arte, como primordial manifestação estética do sensível, estabelece hoje uma relação de cumplicidade com as tecnologias, e a criação tecnoartística resulta da condição em que a arte e o artista são dominados pelas tecnologias digitais. A própria música e a forma de a fazer foram alteradas através dos novos meios tecnológicos (LOPES, 1990), que, por sua vez, também vieram alterar o contexto em que a música se consome, aliando-se a conceitos estéticos através da multimédia.

Tendo como produto final o invisível, a música é a mais subjectiva das formas de arte e a que mais vai ao encontro da relação do homem com o 
sobrenatural. Seguindo essa lógica, é possível ponderar e existência de alguma afinidade entre música transe e o xamanismo, se encarados na perspectiva de uma experiência de transe e da relação cosmológica do homem com outros mundos. Da mesma forma que aos antigos rituais tribais são associadas substâncias psicoactivas, para potenciar estados alterados de consciência, também nos rituais actuais, nomeadamente nas festas transe, é possível essa associação, já que a música tem um efeito diferente sob o consumo de drogas.

\section{Do xamã ancestral ao $D J$ como xamã pós-moderno}

As tecnologias multimédia, enquanto possibilitadoras de experiências multissensoriais, podem permitir experiências psicadélicas através da (experiência) multimédia. Enquanto os antigos xamãs utilizavam cânticos, tambores, luz do fogo e sombras nocturnas acentuadas pela lua cheia, os técnicos de hoje utilizam as novas tecnologias. Mircea Eliade definiu o xamanismo como "técnica arcaica do êxtase" (ELIADE, 2002): a música electrónica e todo o seu universo multimédia poderão ser técnicas modernas do êxtase, tendo por base um xamanismo electrónico, e o DJ como elemento-guia? Talvez, se este assumir o papel do xamã, como mediador do binómio ego e inconsciente. Mas encantar uma audiência não implica, no entanto, ter o dom de recriar uma sessão xamânica. O xamã transcende a sua consciência em prol do outro sujeito, mas o mesmo não acontece com o $D J$, já que ele não se transcende - apenas propicia essa situação para o outro. Pode, no entanto, assumir-se como o guia que proporciona a abertura de canais, ancorado nas relações entre homem-máquina e música-tecnologia, e que permite aos nativos a projecção para lá da sua individualidade.

Um novo xamanismo pode ter despertado da sociedade tecnológica, recriado como tecnoxamanismo, tendo encontrado, transversalmente ao culto da música electrónica, uma nova afirmação no ritual pós-moderno das festas transe. O DJ, comparado ao xamã das culturas tribais, com as devidas 
adaptações ao contexto actual, pode também definir-se como xamã cibernético, proporcionando, através da multimédia e dos mantras tecnológicos, vibrações e estados de espírito comuns à sua cibertribo (FERREIRA, 2007).

\section{As tecnologias como veículos do neoxamanismo}

Direccionando o papel da mediação para a própria tecnologia e assumindo-a como elemento de guia, terá ela uma faceta xamânica? Existem no xamanismo três grandes regiões cósmicas ligadas por um eixo central, que é a terra. Este trinómio pode também ser traduzido por "consciência, tecnologia e transcendência", assumindo como eixo central a tecnologia, mediadora entre as outras duas regiões, em que actua como veículo. Os mundos virtuais que imaginamos e o mundo real, ao qual não podemos escapar, situam-nos entre a máquina e o sonho, numa polaridade denominada de tecnomisticismo (DAVIS, 2002). A tecnologia pode não ter uma faceta xamânica per si, mas tem a faculdade de potenciar a manifestação xamânica, se entendermos a tecnologia como uma extensão da mente humana. Nos rituais transe, o VJ (video jockey), como criador e mediador de efeitos visuais, possibilita e estimula a actividade do imaginário, através da projecção de figuras tridimensionais, psicadélicas e alienígenas. Por seu lado, o DJ, também criador e mediador de efeitos sonoros, pode proporcionar o mergulho em mundos imaginários através da sua música e das oscilações melódicas, rítmicas e de volume que induz. Através de toda essa atmosfera tecnológica, intensa e repetitiva, é possível a manipulação da intensidade de dança e, por conseguinte, do nível de alienação associado, em que, quanto maior for a entrega do ouvinte, mais facilmente se desprende do que o rodeia para entrar num universo só seu.

Como técnica do mundo maquinal que cria simulações, a tecnologia multimédia é um elemento gerador, no sentido de ser a responsável pela criação de algo novo. Por outro lado, ao recriar a existência do mundo imaginário e alternativo, permite uma amplificação dos canais de ligação entre 
dois mundos e, ao assumir-se como elemento catalisador, pode comportar-se como veículo xamânico. Apesar de não ser o caminho para o êxtase, para a transcendência, ou para a ruptura com a condição profana, proporciona um dualismo assimétrico entre oposições como espiritual e material, incorpóreo e corpóreo, interior e exterior (FERREIRA, 2007).

A tecnologia pode não ser xamânica, mas pode ter uma faceta xamânica, da mesma forma que a multimédia pode não ser, por si só, a geradora de emoções, mas pode ser um veículo com o dom de as amplificar, ao conseguir dilatar a abertura de canais sensoriais e remover os bloqueios com o mundo natural, criados ao longo dos anos.

\section{Do ritual tribal ao ritual multimédia}

As festas transe proporcionaram um reencontro com o mundo natural e tribal, mas o que lhes permitiu essa faculdade? Considerando as novas tecnologias como condutores do mundo pós-moderno e as festas como manifestações rituais desse pós-modernismo, terão os aparatos multimédia a supremacia desses neorrituais, que a noite transforma um mundo fictício e mimético e que o dia volta a trazer à sua essência tribal, ou o revivalismo arcaico que se vivencia nas festas nada tem a ver com as novas tecnologias?

A essência dos primitivos rituais de dança e a produção de estados alterados de consciência é similar à das festas de música electrónica da sociedade actual, e a história das raves poderia ter começado há milhares de anos, quando os primeiros homens viviam nas cavernas e respiravam o fumo das fogueiras (FERREIRA, 2007). Se um dos objectivos dos frequentadores das festas é a procura do êxtase, ou do transe, e sendo essas formas de expressão essencialmente humanas, poderão prescindir das tecnologias multimédia? Talvez sim, se considerarmos que esses estados e espírito já eram antes invocados e vivenciados, sem a existência delas. No entanto, situando o ritual no contexto temporal em que emergiu, não é fácil isolar as tecnologias da sua concretização, 
quando elas são usadas para a consolidação de um todo, e principalmente quando o multimédia é essencial para criar um ambiente musical e estético, obedecendo às tendências das quais não se pode dissociar.

A música é um elemento fundamental nas festas, e entendê-la como dependente directa da energia e da electrónica é conferir ao papel das tecnologias uma imediata posição crucial em todo o processo, já que a componente musical do ritual não se concebe sem os dispositivos tecnológicos. Dificilmente, o ritual pós-moderno seria possível no seu todo sem a omnipresença da tecnologia, que age de forma subtil, mas não por isso menos manipuladora, sobre nativos da tribo transe, que viajam num cenário tribal e simultaneamente futurista, como espaço físico e mental de concretização do ritual.

É possível dançar ao som de instrumentos rudimentares de percussão, e atingir estados de transe através da repetição do som e da dança, mas não é possível dançar transe psicadélico sem a electricidade, a electrónica, a tecnologia. O ritual acontecerá sempre que houver intenção prévia para tal, e sempre que estiverem reunidos os elementos básicos para que isso aconteça, seja com o fogo, seja com o multimédia, seja com ambos, seja com tambor, seja com sampler, seja com ambos também. Mas a festa transe, tal como a conhecemos, e considerando os sinais evolutivos que tem apresentado, teria continuidade se, de forma abrupta, fosse privada das tecnologias em todos os aspectos a que se estende? Na secção seguinte, espera-se clarificar essa e outras questões que estão na base desta investigação, através dos resultados das entrevistas com os peritos e de algumas reflexões resultantes da observação participante, enquanto complementos da pesquisa bibliográfica já apresentada.

\section{Trabalho de campo}

A primeira pergunta colocada consistiu em perceber se o xamanismo, como espécie de sistema espiritual, poderia ter alguma afinidade com as festas transe. Apesar de, no ritual xamânico, partir-se do princípio que todos 
os elementos têm uma intenção de participação xamânica, já o mesmo não acontece nas festas, em que, da mesma forma que muitos procuram uma experiência mística, de alienação e ligação ao todo cósmico, outros nem nunca consideraram que poderiam estar a vivenciar uma jornada xamânica, mesmo estando sob o efeito de experiências psicotrópicas que possam sugerir vivências semelhantes. A festa pode ainda ser encarada como um mero espaço de entretenimento, principalmente se analisada no contexto actual, e sob a perspectiva de frequentadores recentes, que dificilmente lhe reconhecem a faceta mística inicial. No entanto, a verdadeira essência e o verdadeiro espírito da festa sugerem e comprovam paralelismos com o xamanismo, desde a presença do elemento-guia à pré-disposição dos nativos em querer participar no ritual, à ligação com a natureza e ao sentimento de união perante a experiência de alienação, que pode ir para além da simples metáfora. Aqueles que tiveram o privilégio de participar dessa experiência continuam a partilhar esse horizonte, mesmo se aplicado parcialmente à realidade actual, já que foi expandido antes de o fenómeno da massificação ter vindo limitá-lo.

Tendo-se focado anteriormente a questão do xamanismo, foi questionado aos $D J s$ se alguma vez se sentiram no papel de um xamã. O DJ Goa Gil mencionou que se sente um xamã sempre que toca, levando o público e acompanhando-o na sua jornada, enquanto o DJ Menog afirma que se sente um xamã quando tem na mão a "chave" para proporcionar uma viagem ao público. A dança surge para os $D J s$ como um estímulo de resposta à própria música: criao-se assim um elo entre eles, o público, a música e a dança. Ambos fizeram referência à viagem e têm consciência de que são os mediadores dessa viagem, proporcionada ao público através da música, que, por conseguinte, leva à dança. A cabine de som do $D J$ assemelha-se na maioria das vezes a um altar, o que remete, por si só, para uma atmosfera de características rituais. Muitos $D J s$ vestem a pele do xamã, embora essa faceta esteja mais limitada ao contexto do transe do que a outras do cenário musical electrónico. No entanto, mesmo confinados a esse estilo, nem todos assumem 
essa vertente mais mística e espiritual da música e de todo o ritual envolvente - é, por norma, mais visível em artistas mais antigos.

Acerca das tecnologias que utilizam para desenvolver o seu trabalho como DJs, de uma forma geral, todos utilizam avançados equipamentos de som e de softwares, sendo comum ver nas festas equipamento tecnológico com alguma envergadura e de marcas reconhecidas pela sua qualidade. Ainda na linha do xamanismo, foi questionado aos entrevistados se acham que a tecnologia tem uma faceta xamânica, numa perspectiva de veiculadora de emoções. Apesar de permitir amplificar sensações, aspirações xamânicas ou propiciar ambientes com esse intuito, a tecnologia não tem para eles essa faceta, mas pode servir como ferramenta para esse fim. Sendo a evolução tecnológica um produto da evolução do homem, e o ritual pós-moderno uma evolução do ritual ancestral, é normal que a esse processo evolutivo se vão acoplando técnicas e ferramentas, específicas de cada momento. Se um ritual pós-moderno pressupõe momentos de aspiração xamânica, é também normal que as tecnologias multimédia estejam presentes e sejam utilizadas como ferramentas para esse fim, já que são uma inerência da própria realidade.

Relativamente ao papel que a tecnologia possa desempenhar em todo esse contexto, perguntou-se até que ponto a festa seria possível sem a sua presença - e qual a sua responsabilidade no acontecimento do ritual. Mais uma vez foi reforçado o papel das tecnologias como veículo, e não como fonte, na medida em que, apesar de serem um elemento potenciador do ritual, este não depende directamente delas para acontecer. No entanto, ao mesmo tempo, elas revelam-se como indispensáveis, ainda que apenas por questões técnicas. Responder a essa questão é uma tarefa ambígua, comprovada pela não linearidade das respostas obtidas. É facto que as tecnologias são o suporte para o todo da festa, desde as infraestruturas básicas, passando pela componente multimédia, até à música electrónica. Assim, a tecnologia poderá ser responsável pela festa, mas talvez não pelo ritual, na sua perspectiva mais humana e espiritual, já que o ele surgiu antes 
da festa, sendo esta apenas o resultado de um processo evolutivo. A música, como um dos elementos centrais do ritual, pode prescindir das tecnologias, se elas forem substituídas por jambés ou por outros instrumentos de percussão semelhantes, desde que emitam sons dançáveis e salvaguardem assim a música e a dança. A componente visual multimédia não se pode dissociar das tecnologias, mas apesar do importante papel que a decoração e toda a componente visual possam ter, não deixam de ser secundárias, porque, apesar de serem frequentes, são uma componente da qual uma festa pode prescindir. Remetemo-nos assim para um ritual, sem efeitos visuais e sem música electrónica em altos decibéis, que é perfeitamente concebível, mas, no entanto, perdemos também a legitimidade de chamá-lo festa transe, pelo menos em conformidade com a ideia pré-concebida que se tem dela.

Tendo a música electrónica uma relação directa com a tecnologia, foi também questionado aos entrevistados se consideram que o culto dessa música possa ter despertado uma nova relação entre os homens e as máquinas. Todos consideram que há uma nova relação entre o homem e a máquina, no sentido do instrumento de suporte que garante a performance artística e as emoções que a partir daí possam advir. A música electrónica é um fruto dessa relação positiva e da capacidade que as máquinas têm de poder recriar dados que o homem tem na sua mente, transformando-os em melodias e permitindo, através delas, moldar estados de espírito.

Tomando a festa transe como uma espécie de ritual, perguntou-se também aos entrevistados se, mediante a sua experiência no meio, a consideram como uma recriação tribal. O participar de uma festa permite compreender o porquê de ser uma recriação tribal, não só pela relação afectiva que é criada entre os participantes, como também pela envolvência que proporciona em todos os sentidos. Há elementos comuns entre todos e partilha-se o estado de espírito através da dança e da vontade de expansão individual, que forma a expansão colectiva. As antigas celebrações tribais tinham como suporte o fogo e o luar; daí privilegiarem-se as noites de lua cheia para colmatar a 
escuridão nocturna. Apesar de actualmente essa questão estar ultrapassada pela técnica, na maior parte das festas, existem ainda fogueiras e muitas são agendadas para noites de lua cheia, ou ainda com o intuito de coincidirem com fenómenos astronómicos, como eclipses, equinócios e solstícios, também símbolos de veneração dos rituais ancestrais.

O significado da palavra transe no âmbito desta investigação remete para o transe como género musical, ao transe psicadélico, ao Goa transe e outros, que têm sido citados ao longo deste projecto. No entanto, um estado de transe também pode significar uma alteração do estado de consciência e, nesse sentido, perguntou-se aos entrevistados se é isso que se pretende, através do transe como género musical. O transe psicadélico consegue remeter os seus ouvintes para estados de transe, se houver da sua parte pré-disposição para tal, e se essa for também a intenção do $D J$ e da própria música. Dentro desse mesmo estilo, algumas melodias são concebidas especialmente para terem um efeito mais hipnótico a um nível mental - direccionadas para a viagem -, enquanto outras são feitas para terem um efeito de movimento e, portanto, a um nível mais físico. A pretensão do estado alterado de consciência pode assim ser logo condicionada à partida. No entanto, esse estilo de música é inegavelmente propício à envolvência e ao inebriamento, em maior ou menor grau de alienação, que, por sua vez, variam também segundo a intencionalidade. Esse estado alterado de consciência é também potenciado ao conjugar a música com substâncias psicoactivas, que aumentam a capacidade de percepção e potenciam as reacções a determinados estímulos, gerando autênticos estados de transe. Apesar do consumo mais banal do haxixe e da marijuana, é principalmente com o MDMA (metilenodioximetanfetamina) e com o $L S D$, aliados à música e à dança, que se consumam as viagens.

Quanto aos objectivos inerentes à organização de uma festa, a pergunta foi apenas direccionada a Artur Mendes e a Pedro Carvalho, pelo facto de a sua experiência e o seu conhecimento do meio também se traduzirem ao nível da produção do evento. Numa primeira resposta, ficamos a saber que, com 
a organização de uma festa ou de um festival, pretende-se essencialmente proporcionar novas experiências, cósmicas. Há pretensões ambientais, artísticas e de evolução pessoal dos próprios frequentadores, e ainda um lado social, artístico e espiritual, potenciador da experiência humana num ritual em que se coabita a partilha. Para além dessa vertente mais humanizada, salienta-se ainda o seu actualmente rentável lado comercial. O festival é um evento de maiores dimensões e com uma duração mais longa, o que permite uma maior afluência de pessoas. O investimento a todos os níveis é bastante superior e, por norma, também conta com um público mais selectivo, fazendo com que se mantenha o espírito mais próximo ao inicial das festas transe.

Sendo Artur Mendes e Pedro Carvalho ambos actores de renome do Boom Festival, eles foram desafiados a assinalar o que terá mudado no festival em dez anos. O primeiro assinala o grande crescimento do festival, visível em termos da afluência do público, pela abertura a novas tendências musiciais e a uma maior diversidade artística. O psicadelismo como filosofia vigente das festas, em particular, tem-se mantido particularmente activo no Boom, mas agora acoplado ao hedonismo e ao activismo ambiental, numa cultura independente e multidisciplinar. Para Carvalho, para além da mudança de local, de gerência e de orientação, o Boom Festival passou da simples festa transe para um festival internacional de culturas alternativas. Criador da versão inicial do festival, ele salienta a diferença entre as motivações que estavam na base do Boom Festival 98, e as actuais, que, apesar de continuarem a promover a mensagem inicial, têm meios e motivações diferentes.

Dadas as características únicas desse tipo de evento, já anteriormente contextualizado como sendo uma recriação tribal e tendo as características de um neorritual, perguntou-se o a ambos se fará sentido atribuir um tipo de perfil específico aos nativos que o frequentam. É visível que deixou de haver tanta diferenciação entre estilos, por estarem cada vez mais embaralhados, quer em termos de tendências musicais, quer na apresentação. As roupas fluorescentes eram uma constante das festas e faziam parte de toda a componente estética, 
também vocacionada para a criação de determinados efeitos visuais, mas hoje aparecem com muito menos frequência. Os freaks que usavam rastas eram imediatamente identificados como adeptos do transe e das festas: hoje, é perfeitamente normal ver esse estilo associado a outras tendências. No entanto, um observador mais atento consegue identificar um nativo, ainda que já o tenha sido em tempos idos, já que remanesce sempre um elemento denunciador, no bom sentido.

Voltando às tecnologias multimédia, os peritos foram ainda questionados acerca da importância atribuída à decoração e às projecções visuais numa festa. As tecnologias multimédia, para além de servirem de alicerces na criação de todo o espaço estrutural e cénico e de sustentarem toda a componente musical, são ainda um dos pontos fortes na decoração e na encenação das festas. Essa presença é, no entanto, variável, dependendo de vários factores que passam normalmente pelos critérios das próprias produtoras - umas privilegiam mais e outras menos a componente visual.

Relativamente ao papel assumido pelas projecções multimédia, elas são cada vez mais importantes nesse género de eventos, com destaque para o papel da robótica, do laser e das projecções vídeo, como elementos que permitem ao público o contacto com universos visuais psicadélicos. Quanto a outros efeitos visuais encontrados nas festas, para além dos multimédia, é destacada ainda a importância de outras formas de expressão visual, nomeadamente de manifestações artísticas como a pintura, a escultura, as performances temáticas e, ainda, a forma como o público se veste e dança. Considerou-se ainda que todos esses elementos têm um carácter interactivo, já que fazem parte de um todo, influenciando-e mutuamente. A decoração pode ir desde meras luzes negras espalhadas por todo o espaço, reflectindo-se em painéis de cores fluorescentes, até ao apurado trabalho de artistas plásticos na criação de cenários. Todos esses efeitos, bem como determinadas actuações que utilizam efeitos luminosos, com luzes ou fogo, têm o seu ponto alto durante a noite, sendo concebidos quase 
exclusivamente para o ambiente nocturno. Durante o dia, é possível encontrar outros tipos de performance, que estabelecem um paralelismo entre os cenários futuristas da noite e os cenários tribais do dia.

Foi ainda questionado a Pedro Carvalho se ela acredita na existência de um paralelismo entre os aspectos sonoros e os aspectos visuais de uma festa. Ele acredita que há uma ligação, na qual a vontade de expansão humana se materializa de forma sonora através da música e de forma tridimensional através da decoração. Como todos os elementos componentes restantes da festa têm um carácter interactivo, o áudio e o vídeo têm uma relação directa, em que a intensidade das projecções multimédia varia de acordo com a intensidade da música. Existe, então, um paralelismo total, porque são dois elementos essenciais, já que sem música não há festa, e, mesmo que se prescinda do grande aparato de projecções multimédia, nunca foi constatada uma festa sem componente visual, ainda que ele se restrinja a um simples pano de motivos psicadélicos, colocado estrategicamente na cabine do $D J$. A decoração é o elemento subliminar mais importante na simbiose entre o indivíduo e a festa; com efeito, é do paralelismo entre o elemento subconsciente que se vê e o elemento consciente que se ouve que a festa remanesce.

Como complemento a uma das questões já abordadas antes, nomeadamente sobre a possibilidade de as tecnologias serem ou não um veículo de emoções, foi por último questionado se as tecnologias nesse contexto poderão ser consideradas uma extensão artificial dos sentidos. Esse conceito não abrange as novas formas de realidade que uma festa pode propulsar. A interactividade existente é orgânica, já que as tecnologias por si não têm capacidade de mudar a percepção, a não ser que haja intenção por parte do homem. A importância da intenção era já ressalvada, atrás, nas respostas de Goa Gil. A expansão dos sentidos é, citandoó, "uma condição primordial da consciência humana", que precede a existência das tecnologias e que não depende delas. O homem e as tecnologias produzem uma realidade que, segundo Pedro Carvalho, é natureza, 
conferindo assim um carácter natural às tecnologias, em oposição ao artificial. "O artificial do passado é o natural de hoje. Tudo provém da matéria. Estamos tão perto do átomo como a máquina."

Podemos considerar que a expansão dos sentidos é um desígnio humano, não havendo nada de artificial nessa intencionalidade, e que, apesar de as tecnologias não serem em si uma expansão artificial dos sentidos, potenciam essa expansão. Particularmente, se, numa festa, os indivíduos estiverem expostos a música com baixo volume, a expansão sensorial será muito menos acentuada do que se estiverem, como é usual, ouvindo a melodia a elevados decibéis. Não tem de ser, portanto, uma expansão artificial, mais ainda se entendermos a tecnologia como um fenómeno natural, e próprio da evolução do homem.

\section{Conclusões}

O principal objectivo desta investigação prendeu-se essencialmente à tentativa de encontrar respostas a três questões. Na primeira, procurou-se perceber até que ponto o culto da música electrónica terá despertado uma nova relação entre os homens e as máquinas, a arte e as tecnologias, os xamãs do passado e os xamãs actuais. Na segunda, questionou-se a tecnologia enquanto possível detentora de uma faceta xamânica, ao permitir a criação de mundos imaginários e estados de consciência alternativos. Por último, quisemos perceber se as tecnologias multimédia, como extensões artificiais do som, da luz e do próprio local, seriam responsáveis para que o ritual aconteça.

Na primeira questão, concluiu-se que, paralelamente ao culto da música electrónica, advieram novas linguagens, novos rituais e novas relações. 0 compositor criou novos laços de proximidade com as suas ferramentas digitais, e a sua relação com as máquinas, para além de física e afectiva, é também tecnológica, sendo desse conjunto de relações que frui o objecto artístico no caso concreto do $D J$, ele é a música. Como forma de expressão artística e estética, a música entra nessa relação tecnológica, que vai também para além 
da física, na medida em que desperta emoções nos ouvintes. As manifestações multimédia que se encontram nas festas transe são também fruto dessa relação de cumplicidade e de criação tecnoartística, despertada pela interacção entre a tecnologia, o objecto artístico e a psique. O homem apodera-se da máquina e esta apodera-se dele, e os sons electrónicos são catalisadores dessas relações técnicas, artísticas e emocionais, em que as máquinas recriam dados mentais, transformando-os em melodias que vão permitir moldar estados de espírito.

Concluímos ainda que existe uma relação entre o xamã do passado e o xamã do presente, incorporado pela figura do $D J$, assumindo também que o xamanismo tem alguns paralelismos com as festas transe, como consolidado pelo contributo dos peritos e da observação participante. Ambos são o elementoguia de um ritual, ao propiciarem viagens através de estados de consciência alternativos, exteriorizando o som, por um lado, de forma arcaica e, por outro, de forma tecnologicamente sofisticada.

Relativamente à segunda questão, acerca da faceta xamânica da tecnologia, percebemos que as tecnologias não são instrumentos xamânicos, mas veículos que facilitam o acesso a mundos imaginários e a estados de encantamento e de consciência alterados, através da amplificação das emoções. No entanto, aferimos que a possibilidade da existência de um tecnoxamanismo, num dualismo entre o material e o espiritual e o corpóreo e o incorpóreo, depende da vontade do homem. A tecnologia não terá um conceito xamânico por si, mas, enquanto produto de uma criação do homem, pode ter essa aplicação se manipulada para esse efeito e se houver pré-disposição do indivíduo perante o processo.

A evolução tecnológica é um produto da evolução do homem, e o ritual pós-moderno, uma evolução do ritual ancestral. Se o ritual pós-moderno pressupõe momentos de aspiração xamânica, é factor normal as tecnologias multimédia estarem presentes e serem utilizadas como veículos para esse fim.

Quanto à última questão, concluímos que as tecnologias multimédia são elementos necessários para a celebração dos rituais da tribo transe, pois, acima 
de tudo, não deixam de ser um produto da sociedade tecnológica. As tecnologias vieram substituir os processos intuitivos das culturas antigas, e o papel dos antigos xamãs foi redefinido pelos dispositivos multimédia. No entanto, o ritual não se subordina directamente às tecnologias, apesar de serem elementos fundamentais para garantir os aspectos logísticos, técnicos, sonoros e também visuais. O homem primitivo é reprocessado à luz da tecnologia, com quem mantém uma relação íntima, dentro e fora do seu ritual tribal - as tecnologias multimédia se assumem como ferramentas holísticas, que permitem a activação dos sentidos para outros níveis e experiências, tão procurados na festa transe. É possível considerar que as tecnologias não sejam alavancadoras do ritual na sua perspectiva mais humana e espiritual, pois nunca o foram desde os tempos mais remotos da sua existência. Mas a festa transe, tal como a conhecemos, bem como os elementos que a sua essência inspira, dificilmente aconteceria sem a sua presença e, apesar de a componente multimédia não ser de existência crítica, não é totalmente dispensável. As tecnologias ajudaram o desencantamento do mundo, mas os impulsos místicos continuaram a incorporá-las, sobretudo quando se revestem de pretensões xamânicas nas festas transe e ajudam a celebrar o encontro do tribal com o pós-moderno, do espírito com a arte e a tecnologia e do transe com o transe. 


\section{Referências}

CARVALHO, M. Culturas juvenis e novos usos de drogas em meio festivo: o trance psicadélico como analisador. Porto: Campo das Letras, 2007.

CASTELLS, M. A sociedade em rede - a era da informação: economia, sociedade e cultura. São Paulo: Paz e Terra, 2000.

DAVIS, E. Tecnognose: mito, magia e misticismo na era da informação, Lisboa: Editorial Notícias, 2002.

ELIADE, M. O xamanismo e as técnicas arcaicas do êxtase. São Paulo: Martins Fontes, 2002.

FERREIRA, P. Um duplo devir: quando a música eletrônica de pista encontra o xamanismo e o xamanismo encontra as máquinas. 2007. Disponível em: <http://pedropeixotoferreira. files.wordpress.com/2010/01/ferreira2007_duplodevir.pdf>. Acesso em: 21 fev. 2010.

LARKIN, C. Turn on, tune in and trance out, the exploration of entheogens and the emergence of a global techno-shamanic ritual. 2003. Disponível em: <http://www. goagil.com/Larkin\%20Thesis.pdf>. Acesso em: 20 set. 2010.

LOPES, J. "As escritas da abertura na música contemporânea". In: Revista de Comunicação e Linguagens. CECL, n. 10/11, 1990. Disponível em: <http://www.bocc. ubi.pt/pag/lopes-jose-julio-escritas.pdf>. Acesso em: 3 jan. 2010.

MAFFESOLI, M. O tempo das tribos: declínio do individualismo nas sociedades de massa. Rio de Janeiro: Forense, 2000.

MCATEER, M. Redefining the ancient tribal ritual for the 21st century. 2002. Disponível em: <http://www.goagil.com/writings.htm>. Acesso em: 21 fev. 2010. 
1 Faculdade de Ciências Sociais - Universidade Católica Portuguesa. Email: emisimao@gmail.com

2 Faculdade de Ciências Sociais - Universidade Católica Portuguesa. Email: stmagalhaes@braga.ucp.pt 